\title{
PREVALENCE OF GESTATIONAL DIABETES, RISK FACTORS AND ITS OUTCOME IN A TERTIARY HOSPITAL
}

\author{
Shrestha B, Shrestha A
}

Department of Obstetrics and Gynecology, Nepal Medical College Teaching Hospital, Attarkhel, Gokarneshwor-8, Kathmandu, Nepal

\begin{abstract}
Gestational diabetes mellitus (GDM) is defined as any degree of glucose intolerance with onset or first recognition during pregnancy. GDM increases the risk of adverse maternal and perinatal outcome and increases risk of diabetes in mother and child in the future. Prevalence of GDM is increasing all over the world. This is hospital based cross sectional study done in Department of Obstetrics and Gynecology, Nepal Medical College and Teaching Hospital to find out the prevalence of GDM and to trace maternal and fetal risk factors and adverse outcome. In this study, 600 pregnant women were enrolled during 2016-17. Among them 27 (4.5\%) were found to have GDM. Among GDM, four (14.4\%) were $\geq 35$ years old and six (22.2\%) had BMI of $\geq 25 \mathrm{~kg} / \mathrm{m}^{2}$. Caesarean section was more common mode of delivery in women with GDM than without (51.9\% vs $22.2 \%$ ). Increased prevalence shown in this study necessitates universal screening of GDM.
\end{abstract}

\section{KEYWORDS}

Gestational diabetes mellitus, glucose intolerance, prevalence, perinatal outcome

\section{CORRESPONDING AUTHOR}

Dr. Biloni Shrestha (Vaidya)

Assistant Professor,

Department of Obstetrics/Gynecology,

Nepal Medical College and Teaching Hospital,

Attarkhel, Gokarneshwor-8, Kathmandu, Nepal

Email: drbiloni@hotmail.com 


\section{INTRODUCTION}

Gestational diabetes mellitus (GDM) is defined as any degree of glucose intolerance with onset or first recognition during pregnancy. ${ }^{1}$ GDM increases the risk of adverse maternal and perinatal outcome and also increases risk of future diabetes to the mother and their child. ${ }^{2}$ Maternal complications of GDM includes polyhydramnios, pre-eclampsia, prolonged labor, obstructed labor, caesarean section, uterine atony, postpartum hemorrhage and infection. Fetal and neonatal complication includes spontaneous abortions, intra uterine death, stillbirth, congenital malformation, shoulder dystocia, birth injuries, neonatal hypoglycemia and infant respiratory distress syndrome (RDS). ${ }^{3,4}$ To reduce these adverse effects of GDM, it is necessary to diagnose early and treat GDM.

International Diabetes Federation (IDF) in 2017 estimated that in 2017 there were 451 million (age 18-99 years) people with diabetes worldwide. Twenty-one million thirty thousand (16.2\%) live births had some form of hyperglycemia in pregnancy. Approximately 18.4 million of these cases were due to GDM. The vast majority of cases of hyper-glycaemia in pregnancy were in low and middle-income countries where access to maternal care is often limited. The prevalence of hyperglycaemia in pregnancy increases with age and is highest in women over the age of $45 .^{5}$

There are ethnic and geographic variation in the prevalence of GDM. ${ }^{6-16}$ GDM prevalence was also higher in Aboriginal women than in nonAboriginal women. ${ }^{13}$ Prevalence of GDM also varies with screening test.

In a background of prevalence of increasing trend of GDM in the world and it being a condition which brings serious adverse outcome to mother and baby, we conducted this study at our institution to look at the prevalence of GDM in our place. In addition only a few recent researches were done in the field of GDM in Nepal.

\section{MATERIALS AND METHODS}

This was a prospective hospital based study. The study was done in Department of Obstetrics and Gynecology, Nepal Medical College Teaching Hospital, a tertiary care hospital situated in Kathmandu. It was done over a period of one year from August 2016 to July 2017.

After approval of proposal by Nepal Medical College Teaching Hospital Institutional Review Committee, all the pregnant ladies coming to the antenatal (ANC) visit at 24 to 28 weeks of gestation were enrolled in the study. Pregnant ladies, with previous known history of diabetes were excluded from the study. After taking consent from these ladies, age, pre-pregnant weight, family history of Diabetes Mellietes, obstetric history (previous pregnancy loss, macrosomia) were recorded. BMI was calculated with height and pre-pregnancy weight told by patient. BMI was calculated with formula weight in $\mathrm{kg} / \mathrm{height}$ in meter $^{2}$.

All the enrolled cases were asked to come with nil per orally next day. After confirming of more than $8 \mathrm{hrs}$ of fasting, fasting blood glucose test was done. Seventy-five gm of glucose in $300 \mathrm{ml}$ of water was given orally, to be taken within 5 minutes. Blood glucose test was done again after 2 hrs of ingestion of glucose. If the patient vomits, then the test was repeated next day (both fasting and OGTT).

GDM was diagnosed according to WHO criteria if either the fasting glucose was $\geq 125 \mathrm{mg} / \mathrm{dl}$ or the two hours glucose was $\geq 140 \mathrm{mg} / \mathrm{dl}$. Patients who had positive glucose test were sent for the medical management to the Physician. Maternal outcome and fetal outcome were followed and evaluated at regular ANC visits, during delivery and post delivery till discharge. Adverse events like UTI, HTN (defined as BP $\geq 140 / 90 \mathrm{~mm}$ of Hg) pre-eclampsia and eclampsia were noted for each patient. At the time of delivery, types of delivery and complications were noted. For fetal outcome fetal weight, presence of Neonatal hypo-glycaemia and RDS were recorded. All the data were tabulated and process with software SPSS-16. Fisher's exact test was used for data analysis. Statistical significance was considered as $P$ value $\leq 0.05$.

\section{RESULTS}

In this study 600 out-patient pregnant ladies were enrolled from department of Obstetrics and Gynecology, Nepal Medical College Teaching Hospital. Among them, 27 cases (4.5\%) were found to have GDM.

Among those with GDM (27), four cases (14.8\%) were of 35 years or above, but among non GDM (573) only 12 cases (2.1\%) were of 35 years or above $(\mathrm{P}$ value $=0.0041)$. $\mathrm{BMI} \geq 25 \mathrm{~kg} / \mathrm{m}^{2}$ were seen in six (22.2\%) GDM patients and 18 (3.1\%) in non GDM $(P$ value $=0.0004)($ Table 1$)$.

Among 27 GDM pregnant ladies we found significant family history and obstetric history of five cases (18.5\%) each, where as among non GDM three $(0.5 \%)$ cases were with significant family history and $17(2.9 \%)$ with significant obstetric history (P values 0.0001 and 0.002 ) (Table 1).

In the study, there were three cases (11.1\%), which were complicated by Gestational hypertension and pre-eclampsia, one case $(3.7 \%)$ had Polyhydramnios and six cases (22.2\%) developed Urinary tract infections among GDM mothers (Table 2). 
Table 1: Risk factors for GDM (Total 600 cases)

\begin{tabular}{lccc|} 
Risk factors & $\begin{array}{c}\text { Among } \\
\text { GDM (27) }\end{array}$ & $\begin{array}{c}\text { Among non } \\
\text { GDM (573) }\end{array}$ & $\begin{array}{c}\text { P } \\
\text { value }\end{array}$ \\
Age $\geq 35$ & $4(14.8 \%)$ & $12(2.1 \%)$ & 0.0041 \\
BMI $\geq 25 \mathrm{~kg} / \mathrm{m} 2$ & $6(22.22 \%)$ & $18(3.14 \%)$ & 0.0004 \\
$\begin{array}{l}\text { Previous } \\
\text { pregnancy loss }\end{array}$ & $5(18.5 \%)$ & $17(2.9 \%)$ & 0.0020 \\
$\begin{array}{l}\text { Diabetic parents } \\
\text { and siblings }\end{array}$ & $5(18.5 \%)$ & $3(0.5 \%)$ & 0.0001 \\
\hline
\end{tabular}

Fisher's exact test one-tailed $\mathrm{P}$ value

Delivery complicated with vacuum delivery was one (3.7\%) among GDM and 19 (3.3\%) among non GDM (P value $=0.6079)$. There were 14 cases (51.9\%) of GDM and 127 (22.2\%) of non GDM had LSCS in the study $(\mathrm{P}$ value $=0.0010)($ Table 3$)$.

\section{Table 2: Complications of GDM at ANC (Total 27} cases)

\begin{tabular}{lc|} 
Complications & Among GDM (27) \\
$\begin{array}{l}\text { Gestational hypertension/ } \\
\text { preeclampsia }\end{array}$ & $3(11.1 \%)$ \\
Polyhydramnios & $1(3.7 \%)$ \\
UTI & $6(22.2 \%)$ \\
\hline
\end{tabular}

Table 3: Delivery complications (Total 600 cases)

\begin{tabular}{lccc|} 
Complications & $\begin{array}{c}\text { Among } \\
\text { the GDM } \\
(\mathbf{n}=27)\end{array}$ & $\begin{array}{c}\text { Among } \\
\text { non GDM } \\
\mathbf{( n = 5 7 3 )}\end{array}$ & $\begin{array}{c}\mathbf{P} \\
\text { value }\end{array}$ \\
$\begin{array}{l}\text { Instrumental } \\
\text { delivery }\end{array}$ & $1(3.7 \%)$ & $19(3.3 \%)$ & 0.6079 \\
LSCS & $14(51.9 \%)$ & $127(22.2 \%)$ & 0.0010 \\
\hline
\end{tabular}

Fisher's exact test one-tailed $P$ value

Table 4: Neonatal complications (Total 600 cases)

\begin{tabular}{lccc|} 
Complications & $\begin{array}{c}\text { Among the } \\
\text { GDM (n=27) }\end{array}$ & $\begin{array}{c}\text { Among } \\
\text { non GDM } \\
\mathbf{( n = 5 7 3 )}\end{array}$ & $\begin{array}{c}\text { P } \\
\text { value }\end{array}$ \\
$\begin{array}{l}\text { Macrosomia } \\
\begin{array}{l}\text { Infant respiratory } \\
\text { distress } \\
\text { syndrome }\end{array}\end{array}$ & $3(0.5 \%)$ & \\
$\begin{array}{l}\text { Perinatal } \\
\text { Mortality }\end{array}$ & $1(3.7 \%)$ & $4(0.7 \%)$ & 0.2063 \\
\hline
\end{tabular}

Fisher's exact test one-tailed P value

There was no significant increased rate of complications in neonates among GDM as compare to non GDM. Infant RDS was one (3.7\%) among GDM and four (0.7\%) among non GDM cases $(P$ value $=0.2063)$. Perinatal mortality was also found non-significantly increased among
GDM as compare to non GDM one (3.7\%) six (1\%) $(\mathrm{P}$ value $=0.2767)($ Table 4$)$

\section{DISCUSSION}

According to the International Diabetes Federation in 2017, $16.2 \%$ of live births had some form of hyperglycemia in pregnancy and an estimated $85.1 \%$ were due to GDM. ${ }^{5}$ This is very high prevalence. Our study showed the prevalence of GDM in our hospital is $4.5 \%$, and this prevalence rate is not low. Similar result was found in the study done in Turkey by Erem et al where prevalence of GDM was found $4.8 \%{ }^{17}$ In contrast to these Nwaokoro et al found the prevalence of GDM 19\%, where the sample size was small with only 100 cases. ${ }^{18}$

The prevalence of GDM in India varies in different parts of the country, depending on the geographical locations and diagnostic methods used. The prevalence of gestational diabetes has been reported to range from $7.8 \%$ in Kashmir, ${ }^{19}$ $9.5 \%$ in Western India, ${ }^{20}$ and $18.9 \%$ in Chennai. ${ }^{21}$ In more recent studies, using different criteria, prevalence rates as high as $35 \%$ from Punjab, ${ }^{22}$ and $41 \%$ from Lucknow have been reported. ${ }^{23}$ The geographical differences in prevalence have been attributed to differences in age and/or socioeconomic status of pregnant women in these regions.

Nepal is a small country with different geographic variations and with different ethnicity. A very few studies have been done with variable results. Prevalence of $4.5 \%$ of GDM in our study is quite high in compare to other studies done in Kathmandu. Prevalence of GDM in a study done in Tribhuvan University Teaching Hospital (TUTH) Kathmandu was $0.6 \%$, in Dhulikhel Hospital, it was $0.75 \%$ and in Kathmandu Medical College, it was $1.58 \% .^{24-26}$ In all these studies screening test was done with $50 \mathrm{gm} \mathrm{GCT}$ and confirmation done with 75 gm OGTT. These studies were done long time back as compared to our study. This may be the cause for less prevalence of GDM in these studies.

Prevalence of GDM was high in a study done in Terai region of Nepal. In the study done in National Medical College Birgunj, using GCT and OGTT the prevalence was $8.29 \% .{ }^{27}$ The reason may be due to geographical difference and ethnic variation compared to Kathmandu. Such ethnic and geographic differences in the prevalence of GDM also seen in other studies. ${ }^{6-16}$ Another study done in similar climatic region and similar ethnical group in Nepal, done by Yadav et al showed the prevalence of $4.8 \% .^{28}$ Total number of GDM positive in the study done by Thapa et al was $2.5 \%$ according to WHO criteria and $6 \%$ according to IADPSG criteria. ${ }^{29}$ Thapa et al did the study in three different rural districts of Nepal with different geographical area and different ethnical groups, but there were non-significant difference 
in GDM prevalence by district and ethnic group. This type of difference was seen in the study done by Ferrara A. ${ }^{11}$ GDM is in increasing trend world wide,,$^{7,12,14,15}$ and same can be seen in Nepal. ${ }^{24-29}$

Maternal age is strongly associated with GDM. In many studies it was reported that prevalence

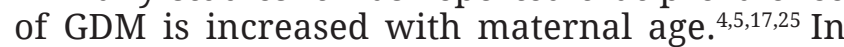
our study prevalence of GDM is also significantly increasing with maternal age. Prevalence of GDM $\geq 35$ years was $14.8 \%$, whereas age less than 35 was $2.9 \%$. Type II diabetes mellitus is usually occurred in elder people. This may be the reason of increase prevalence of GDM in $\geq 35$ years pregnant ladies.

Obesity is another risk factor for GDM. Most of the studies showed that high BMI had more prevalence of GDM than low BMI., $, 6,7,10,16,17$ In our study like other studies significant risk of GDM was seen with increased BMI.

Significant positive obstetric and family history was important risk factors for GDM in this study. Previous pregnancy loss was found in $18.5 \%$ among the GDM whereas only $2.9 \%$ among non GDM. This may be due to uncontrolled hyper glycaemia in previous pregnancy. Similar result also found related with positive family history. Family history is the main risk factor for Diabetes II and GDM is also one of the future risks for Diabetes II. This may be the reason for possibility of type II Diabetes in future and is shown by several studies..$^{10,18}$

The maternal complications of GDM are hypertension, preeclampsia, urinary tract infection, polyhydramnios, increased operative intervention during delivery and future Diabetes Mellitus. ${ }^{3}$ All the diagnosed GDM cases were well treated with diet, insulin and termination of pregnancy done when required.

There was no significant differencein instrumental deliveries, but LSCS was significantly high, 51\% among GDM and 22.2\% among non GDM. Similar finding was seen in a study done by Siribaddana et al..$^{30}$

Fetal complications were not significantly increased among GDM in the study. This may be due to appropriate treatment done at time during pregnancy.

Prevalence of GDM is increasing even in Nepal, so universal screening is necessary. Accurate diagnosis and treatment at right time reduces fetal and maternal complications. It is necessary to go for better way of screening, to make it affordable for universal screening.

\section{ACKNOWLEDGEMENT}

My special thanks to faculty members and my residents, who helped me in collecting the data.

\section{REFERENCES}

1. Metzger BE, Coustan DR. Summary and recommendations of the Fourth International Workshop-Conference on Gestational Diabetes Mellitus. Diabetes Care 1998; 21: 161-7.

2. Danam P. GDM and subsequent development of overt Diabetes mellitus. Dan Med Bull 1998; 45: 495-509.

3. Casey BM, Lucas MI, Mcintire DD, Liezemo KJ. Pregnancy outcomes in women with GDM compared with the general obstetric population. Obstet Gynecol 1997; 90: 869-73.

4. Kanika KR, Jajoo S, Hariharan C, Samal S. Prevalence of gestational diabetes mellitus, its associated risk factors and pregnancy outcomes at a rural setup in Central India. Int'l J Reprod Contracept Obstet Gynecol 2014; 3: 219-24.

5. Cho NH, Shaw JE, Karuranga S et al. IDF Diabetes Atlas: Global estimates of diabetes prevalence for 2017 and projections for 2045. Diabetes Res Clin Pract 2018; 138: 271-81.

6. Green JR, Pawson IG, Schumacher LB, Perry J, Kretchmer N. Glucose tolerance in pregnancy: ethnic variation and influence of body habitus. Am J Obstet Gynecol 1990; 163: 86-92.

7. Dooley SL, Metzger BE, Cho NH. Gestational diabetes mellitus: influence of race on disease prevalence and perinatal outcome in a U.S. population. Diabetes 1991; 40: 25-9.

8. Beischer NA, Oats JN, Henry OA, Sheedy MT, Walstab JE. Incidence and severity of gestational diabetes mellitus according to country of birth in women living in Australia. Diabetes 1991; 40: 35-8.

9. Berkowitz GS, Lapinski RH, Wein R, Lee D. Race/ ethnicity and other risk factors for gestational diabetes. Am J Epidemiol 1992; 135: 965-73.

10. Solomon CG, Willett WC, Carey VJ et al. A prospective study of pre-gravid determinants of gestational diabetes mellitus. JAMA 1997; 278: 1078-83.

11. Ferrara A, Hedderson MM, Quesenberry CP, Selby JV. Prevalence of gestational diabetes mellitus detected by the National Diabetes Data Group or the Carpenter and Coustan plasma glucose thresholds. Diabetes Care 2002; 25: 1625-30.

12. Ferrara A, Kahn HS, Quesenberry C, Riley C, Hedderson MM. An increase in the incidence of gestational diabetes mellitus: Northern California, 1991-2000. Obstet Gynecol 2004; 103: 526-33.

13. Ishak M, Petocz P. Gestational diabetes among Aboriginal Australians: prevalence, time trend, and comparisons with non-Aboriginal Australians. Ethn Dis 2003; 13: 55-60. 
14. Dabelea D, Bergeon JKS, Hartsfield CL et al. Increasing prevalence of gestational diabetes mellitus (GDM) over time and by birth cohort: Kaiser Permanente of Colorado GDM Screening Program. Diabetes Care 2005; 28: 579-84.

15. Thorpe LE, Berger D, Ellis JA et al. Trends and racial/ethnic disparities in gestational diabetes among pregnant women in New York City, 1990 2001. Am J Public Health 2005; 95: 1536-9.

16. Dornhorst A, Paterson CM, Nicholls JS et al. High prevalence of gestational diabetes in women from ethnic minority groups. Diabet Med 1992; 9: 820-5.

17. Erem C, Kuzu UB, Deger O, Can G. Prevalence of gestational diabetes mellitus and associated risk factors in Turkish women: the Trabzon GDM study. Arch Med Sci 2015; 11: 724-35.

18. Nwaokoro JC, Emerole CO, Ibe SNO, Amadi AN, Dozie INS. Risk factors associated with gestational diabetes among pregnant women in Owerri Municipal Council, South Eastern Nigeria. Asian J Med Sci 2014; 5: 39-46.

19. Raja MW, Baba TA, Hanga AJ et al. A study to estimate the prevalence of gestational diabetes mellites in an urban block of Kashmir valley (North India). Int'l J Med Sci Public Health 2014; 3: 191-5.

20. Bhatt AA, Dhore PB, Purandare VB, Sayyad MG, Mandal MK, Unnikrishnan AG. Gestational diabetes mellitus in rural population of Western IndiaResults of a community survey. Indian J Endocrinol Metab 2015; 19: 507-10.

21. Seshiah V, Balaji V, Balaji MS, Sanjeevi CB, Green A. Gestational diabetes mellitus in India. J Assoc Physicians India 2004; 52: 707-11.

22. Arora GP, Thaman RG, Prasad RB et al. Prevalence and risk factors of gestational diabetes in Punjab,
North India: Results from a population screening program. Eur J Endocrinol 2015; 173: 257-67.

23. Gopalakrishnan V, Singh R, Pradeep Y et al. Evaluation of the prevalence of gestational diabetes mellitus in North Indians using the International Association of Diabetes and Pregnancy Study groups (IADPSG) criteria. J Postgrad Med 2015; 61: 155-8.

24. Rana A, Pradhan N, Gurung G, Singh M. Screening Test for Gestational Diabetes. J Institute Med 1997; 20: 26-32.

25. Shrestha A, Chawla CD. The glucose challenge test for screening of gestational diabetes. KUMJ 2011; 9: 22-5.

26. Bajracharya A, Saha R, Shakya A. Pregnancy Outcome in Gestational Diabetes Mellitus. J Kathmandu Med Coll 2014; 3: 107.

27. Mandal F, Gupta S, Rimal B, Kafle D. Prevalence of gestational diabetes mellitus in national medical college \& teaching hospital. Int'l Res J Pharm App Sci 2013; 3: 1-3.

28. Yadav S, Shrestha S, Hamal P, Islam N. Article Maternal age and screening for Gestational Diabetes Mellitus in Nepalese women. Int'l J Curr Resc 2013; 5: 2878-80.

29. Thapa P, Shrestha S, Flora MS et al. Gestational Diabetes Mellitus - A Public Health Concern in Rural Communities of Nepal. J Nepal Health Res 2015; 13: 175-81.

30. Siribaddana SH, Deshabandu R, Rajapakse D, Silva $\mathrm{K}$, Fernando DJ. The prevalence of gestational diabetes in a Sri Lankan antenatal clinic. Ceylon Med J 1998; 43: 88-9. 